\title{
Miranda
}

Revue pluridisciplinaire du monde anglophone /

Multidisciplinary peer-reviewed journal on the English-

speaking world

$18 \mid 2019$

Guerre en poésie, poésie en guerre

\section{Political satire and music: Humorous (and political) songs in Donald Trump's America}

\section{Aurélie Denat}

\section{OpenEdition}

\section{Journals}

\section{Electronic version}

URL: http://journals.openedition.org/miranda/18557

DOI: 10.4000/miranda.18557

ISSN: 2108-6559

Publisher

Université Toulouse - Jean Jaurès

\section{Electronic reference}

Aurélie Denat, "Political satire and music: Humorous (and political) songs in Donald Trump's America", Miranda [Online], 18 | 2019, Online since 17 April 2019, connection on 16 February 2021. URL: http:// journals.openedition.org/miranda/18557 ; DOI: https://doi.org/10.4000/miranda.18557

This text was automatically generated on 16 February 2021.

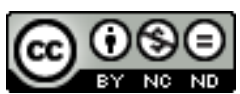

Miranda is licensed under a Creative Commons Attribution-NonCommercial-NoDerivatives 4.0 International License. 


\title{
Political satire and music: Humorous (and political) songs in Donald Trump's America
}

\author{
Aurélie Denat
}

\section{Why study satirical songs?}

1 It all started with the terrorist attacks of November 2015 in Paris. The world was shocked by the events, and among messages of support on Facebook there was a Youtube video, shared thousands of times, by a British comedian who had a satirical show in America. This man, John Oliver, with his show Last Week Tonight, managed to make me (and millions of people) laugh with his take on the tragedy that had struck. My interest in the genre of political satire was born, and this is how I get my news now on what happens in the US and the UK. As I live in France, I watch these videos on Youtube. One of the features of this platform is an algorithm that allows the website to adjust its propositions to what you have watched before. This is how Youtube recommends other political shows like Saturday Night Live for example. This show is different from shows such as Last Week Tonight, the Late Show with Stephen Colbert or the Late Late Show with James Corden in that it is composed of sketches and not stand up comedy (or very little). Among its part-of-life parodies, mock-news and fake TV shows there are humoristic songs, often with a political undertone. The focus here will be on five music videos created during the Trump era, starting from the presidential election campaign 2016 to the mid-term election of 2018. What is the use of humorous songs for political satire? What do they - as musical numbers - add to the overall satirical discourse? The five songs under study have been picked among political shows or Youtube performers that specialise in humoristic and parody songs or sketches.

2 The title of the first video (V1) is Make America Great Again. It was created by the collective Laughter Trump's Hate (LTH). LTH was at the origin of a website mostly composed of funny videos. The sole aim of the website was to prevent the election of 
Trump by shedding light - in a humorus way - on his many faults and dangerous political ideas. The site was discontinued the day following the election for it had failed in its mission. The title is directly inspired by Donald Trump's campaign slogan: "Make America Great Again", today mentioned through its acronym MAGA. The music used here has a 1930s flavour that can also call to mind the musicals of old times. However, the visual style translates more of a 1950s atmosphere. The elements mentioned in the song lyrics relate to events and legislation that go all the way back to slavery. This song bears witness to a division faced by the country and illustrates the saying "ignorance is bliss". The lyrics remind us of a time when sciences (both hard and soft) were not as advanced as they are now. A happy few - straight white males - were blissfully ignorant of the damage their way of life caused to other communities - women, Blacks, Mexican and Jews. The video that accompanies the song serves as a mere illustration of the lyrics. The tone is light, the music is engaging, the tune is pleasing, but the subject and the language used are dark and depressing.

3 The second song (V2) stages a rap battle between Donald Trump and Hilary Clinton and is entitled Donald Trump vs Hillary Clinton. It was created by the Youtube channel Epic Rap Battles of History (ERB), a channel famous for its satirical rap battles. The main features are contradictory figures of pop cultures (Doc Brown vs Doctor Who), fictional and real people (Jack the Ripper vs Hannibal Lecter), non-contemporary historical figures (George Washington vs William Wallace). However, this particular song is a rare instance in which the two persons opposed are both real and contemporary, namely the candidates of the 2016 elections: Donald Trump and Hillary Clinton. The music here is computergenerated. This song was published on Youtube on October 26, 2016, six days after the last presidential debate. This music video is a confrontation between the two politicians where American symbolism is largely present. The language used is colloquial, and verbal assaults are coming from both fronts. This song testifies to a sharp division between the two protagonists.

4 The third music video (V3) is an R'n'B type of song, an excerpt from the 2017 Thanksgiving show of Saturday Night Live. Saturday Night Live is a satirical show, using sketch-like performances to shed light on cultural and political events. The musical number is entitled Come back Barack. The style is close to that of numerous R'n'B music videos of the late 1990 s to the early 2000 s. The music is a ballad sung by three men. It seems, at first, to be a break-up song. The main theme is regret, and the song contains a plea to the former American president, Barack Obama, to come back into office. The language is familiar, but there is no swearing involved. The lexical fields used are those of break-up and romantic relationships. The theme of division is also important, though less blatant than in the other videos, and the type of satire employed is rather light.

5 The fourth song (V4) is also an R'n'B song. It is the parody of an existing song, both of them bearing the title It wasn't me. In the original version by rapper Shaggy, a man is caught cheating on his girlfriend with his neighbour, and his friend advises him to say that it wasn't him. Shaggy sings his part again but the theme has slightly changed. In the Late Late Show with James Corden's version, the duet stages President Trump and Robert Mueller, the man in charge of the investigation on the links between Donald Trump's presidential campaign and Russia, which is viewed as treason. Shaggy who portrays Donald Trump, is an African-American rapper who uses familiar and colloquial language. James Corden, who resorts to a standard language, portrays Special 
Counsel Robert Mueller. The song is then one of confrontation, and division. It aims to question presidential powers, especially as it refers to the dismissal of FBI director James Comey, which led to the appointment of Robert Mueller.

6 The last song (V5), entitled We're stuck in this together, is an excerpt from the Late Show with Stephen Colbert. The style used here is that of musical theatre, involving a piece of American-sounding music, close to country music. The song was especially written for the mid-term elections of 2018. The tune is light and catchy. The main theme is the schism that the country has experienced since the 2016 elections. This division is acknowledged, and the singer asks for re-unification in order to overcome this crisis. This musical number sums up the past two years of Donald Trump's presidency by giving it a metaphorical twist. It also relies heavily on the representation of American identity. Through its metaphorical language and visual representations of the central metaphor ("The US is a submarine"), the song is a call for unity.

7 Studying satire and especially satirical songs can be achieved from different angles. They can be considered as a musical number, a video or a discourse. The latter - our focus here - can be studied through literary analysis or linguistic analysis. The framework chosen here is that of a hybrid field, the child of literature and linguistics: stylistics. The part played by the literary approach will be materialise through the attempts at a definition of satire, in the first part of this paper. The contribution of linguistics will take the form of the use of the Semantic Script Theory of Humour that relies heavily on frame semantics. This theory will be explained in the second part and illustrated by specific examples. These two frameworks will be used in an attempt to answer the following question: how far does humour help the singers reach their target? The answer will be divided into two parts: the first part will be an attempt at a thorough definition of satire; the second part will focus on frame semantics and humour, more specifically on the Semantic Script Theory of Humour.

\section{What is satire?}

8 Satire is not a genre but a form. It is a form in that it it covers any types of work and is not limited by specific characteristics as lengths, genre, subject... Formal satire had a short life-span and no longer exists. Formal satire was a lyrical poem in Ancient Greece, it was tragic, and comprised of an unlimited number of verses. Soon, humour was added and the works that were supposed to be read became performed in theater and so on. The principle of satire interested people much more than the form it took. Today the style of satire is hard to define because of the disparities in the genre, forms, media, and lengths of work seen as satirical. The central principle of satire is to both inform and entertain. Satire attacks dullness more than vice. The satirical work was born from both the indignation of the satirists and their need to convey a message and sometimes even call for action. No matter the genre, the form, the medium or the length, a work of satire binds together, first of all, moral and aesthetic functions. Satire also provides a link between irony and banter, and the perfect fusion of the two is what creates the humour that characterises satire. The satirist has also a crucial role to play in society, educating people by making them laugh. Serious issues are tackled by means of a light style that will enable people to understand the problem and gather the appropriate information. If, nowadays, satire is associated with humour, it was not always the case. At the beginning, satire was a tragic genre, but today it is perceived as a humorous 
form. Humour cannot be explored without mentioning satire as a type of humour alongside light humour, dark humour, dirty humour, etc. The humour of satire relies on exaggeration. It is usually aimed at an individual or an institution seen as authoritative. The central principle of this type of humour is the play on scripts: the transition from one meaning to another creates humour.

In the twentieth century, the difference between satire and mockery began to be blurred. Yet, while mockery tends to remain on the surface, satire has a carefully researched background and goes deep into its subject. In both cases the tone is light, but while mockery is simply mockery and has no substantial foundation, satire supports a well-informed point of view. Today, with the growth of social media, anyone can become a satirist or at least relay satire, only by hitting the "share" button on the websites of social networks. For these types of videos and especially those from such TV shows as V3, V4 and V5, ratings do not include Youtube views. The videos are then spread across the web. Political and News satire is focused on current news. Political satire is a category of News satire that relates to public matters, such as public life, legislation and government. Some satirists, such as LTH and ERB, only exist online, and may finance their creations through the patronage of the internet users and advertising contracts (as is the case of ERB).

Satire can take several forms and lengths, but it is limited in the sense that it needs to follow the rules of a specific mode to exist as such. Satire has to both inform and entertain: it can either be personal or work on a larger scale. Broad (or general) satire targets society in general, or at least a large portion of it, by highlighting its flaws and inconsistencies. This is the case in the third video with the following quote "we didn't know just what we had" (V3) which is a direct reference to the way polls and voters treated President Obama during his second term, giving the control of Congress to the Republicans and making it more difficult for him to reform the country. The whole country then becomes the target of satire. In the case of personal satire, the target is an individual chosen as the poster boy (or girl) of a vice or a specific ideology. In the second video, Donald Trump and Hillary Clinton are both, in turn, the target. "The Art of the Deal" (V2) refers to a book which Donald Trump wrote on negotiations; his track record as a businessman is being grilled because a huge number of his companies have gone bankrupt or are being on trial. Broad versus personal is not the only contrast to be observed in satire; another one is implicit versus explicit.

11

In the case of explicit satire, the individual or the chunk of society that is criticised is directly attacked, the words are used with their denoted meaning. "That's assault brutha" (V2) is a direct attack aiming at Trump as a comment on words he pronounced on tape: "Grab her by the pussy". In implicit satire, the language is metaphorical, and rests on the connoted meaning of the word, as in "I miss those good old carefree days" (V1). In this example, the utterance refers to a time when ignorance was bliss. Everything is implied: women's condition, domestic violence, systemic racism, segregation, slavery, etc.

12 As mentioned earlier on, humour has an advantage: it can help remember information. However, an entire text cannot be humorous; there will be serious moments and lighter ones. It is the balance of the two that makes a text humorous and light even when it deals with deep and rather dark subjects. Humour is used every day to share a point of view or convey a specific message. Humour in general and, more specifically, satire are 
based on context. Puns can only be understood in specific settings. Satire, in particular, depends on recent events, and humour in this case is often temporary: the context of the humorous discourse might soon not be relevant any more, or the references used for the jokes might be outdated. The audience also has an important role to play in the delivery of a discourse. The laughs mark the end of a joke, the lack of reaction shows that the joke is not perceived as funny, and booing may signal its inappropriateness. The discourse has to be written while bearing in mind the targeted audience, their demographic, their beliefs and ideologies, and the setting in which the humorous message will be delivered.

In order to convince its audience, satire has long been constructed with a narrative arc. The discourse of satire is structured in a logical string of arguments that will ultimately lead to the main discussion and the point of view of the satirist on a given subject. One of the main features of satire is also the personal attack of public figures. In the past, satire was differentiated from lampoon, which is a form of mockery aimed at a specific individual. Even though personal satire is not a lampoon, it can sometimes resort to this device. Often used in satire is the comical device known as reductio ad absurdum, which rests on exaggeration. It is a traditional rhetorical strategy whose goal is to show how an opponent's argument, if stretched far enough, can have ridiculous consequences. This device is often used to fight someone's case and show the ridicule behind someone's argument. An example from the corpus would be the reduction of several arguments of Trump to a single sentence: "I'll create jobs tearing down mosques." (V2). Satire is deeply embedded in a specific context, and the use of symbols is not rare. The aim here is to create a sense of identity and cohesion, referring to common knowledge. It is particularly important in these five videos where the main theme is division. This schism is made obvious by references to the Civil War that divided America in the 1860s. The conflict is referred to through the presence of Abraham Lincoln and the use of his own words. The president of the Civil War (whose politics might have triggered it) is physically present in two videos - V2 and V5 although not to the same extent. Here is an excerpt from V5:

STEPHEN COLBERT: But we can't split up that's not what we're about.

Besides, we tried that once.

ABE LINCOLN: And look how that turned out.

In V2, Abraham Lincoln's lines cover the last quarter of the song. Two of his lines are particularly interesting. "Of the people, by the people, for the people" which concludes the song is a famous quote from Abraham Lincoln, taken from the Gettysburg Address given after the victory of the Union (the Northerners) over the Confederates (the Southerners) during the Civil War. In that address, he did not condemn the South, nor vilified the fallen, but asked for unity, just as this fictional Abraham Lincoln is demanding unity. The same process may be observed in the following line: "You got brother blocking brother on their facebook feed". This line has two functions: first, it lessens the volatility of the situation by acknowledging that this "Civil War" mostly takes place on social media; second, it links the situation to Abraham Lincoln's word by transferring one of his quotes to another cultural reality. This quote - "brother fighting brother" - was a reference to brothers being on opposite sides of the war (in neighbouring states), and Americans in general being opposed to one another. We find another reference to American identity, more subtle and aimed at an American audience. Even though government and Church were set apart from each other very early in their history (if not from the very beginning), the United States are a highly 
religious country. This belief of being the people selected by God as stated in "City Upon a Hill speech" was hinted at again throughout the country's History.The most striking and well-known proof is the pledge of allegiance to the American flag ("I pledge allegiance to the Flag of the United States of America, and to the Republic for which it stands, one Nation under God, indivisible, with liberty and justice for all. ") The part of the pledge that interests us here is the phrase "One Nation under God" (added during the Cold War in 1954). In one of the shots from V5, we can see Stephen Colbert standing in front of the voting booth, arms spread on either side of his body, with an overhead projector shedding direct light on his face, talking about God. Another reference to this deep belief in God is a not so subtle allusion, to Matthew's Gospel, chapter 22, verse 39: "Love thy neighbour as thyself". In V5, one of the lines is "You've got no choice but to love thy neighbour," which is a direct reference to this specific verse of the Gospel. In the United States, this quote is essential for it recalls the nation's choice to become independent by uniting the thirteen colonies in spite of their various differences and making them love one another since they were on the same continent. This quote is of such paramount importance that it is even the title of a TV show released in 2013.

Satire heavily relies on those types of cultural references, but it also, to a large extent, rests on humour. The kind of humour used - the shift of script - relies on frame semantics, which will be explored in the second part of this paper.

\section{Verbal humour and frame semantics}

16 In order to understand what verbal humour entails we need to examine two linguistic concepts: frame semantics and the differences between the dictionary definition and the encyclopedic definition. Frame semantics, which is part of cognitive linguistics, states that someone's knowledge is organised through frames (or boxes). This theory of semantics by Charles J. Fillmore acknowledges the existence of two types of entities: profile and base. The base is the knowledge of a conceptual structure that is presupposed by the profile's concept. LARK, for instance, is a profile of the base BIRD. The difference between a dictionary definition and an encyclopedic one lies in the scope of each one. The dictionary definition defines the word itself and its grammatical function and nature, whereas the encyclopedic one explains the concept and the context that the word points at. One word or concept can relate to more than one base. It is then called polysemic. The profile MOUSE, for example, belongs to both bases ANIMAL and TECHNOLOGY. In V2, the word FIRE is used as the profile of two bases in the following case: "You fire celebrities on The Apprentice / Mutha fucka I fire Ben Laden". The first occurrence relates to the base EMPLOYMENT and the second to the base VIOLENCE, for in this case FIRE is a synonym for EXECUTE. The play on the polysemy of a word can also co-occur, as is the case in the following example from V5: "Today we got to pull the lever". This phrase is used as the conclusion of a long metaphor comparing the US to a submarine (this comparison will be examined later on). The zeugma "pull the lever" relates to two meanings. In the context of a submarine, the denoted meaning is used: by pulling the lever, the submarine resurfaces. The second meaning plays on connotations. In the US and the context of elections PULL THE LEVER means "lift the curtain of the voting booth", and by extension "vote". The two meanings are conveyed here, as a way perhaps to show the 
correlation between the two: voting would mean getting out of a difficult situation (as in the case of a sinking submarine). The last example that could be used here is that of a visual pun in V4. The pun relies on the idiom "pants on fire". In this extract, Robert Mueller accuses Donald Trump of being a liar by saying "I think your pants are on fire"; he then uses the idiom in its context. However, smoke emanates from the president's trousers but not fire. The pun could be a visual pun with a double meaning. The fact that there are no flames could be - except for a technical issue - an allusion to another idiom: "There's nos smoke without fire". This could be a reference to the "Witch Hunt", a rhetoric Donald Trump uses to explain why he is the target of FBI investigations while claiming he is innocent of any wrongdoings. It could be a way for the creator of this music video to signal that, according to him, there would be no investigation if there were no wrongdoings.

We can go even further in examining frame semantics by analysing a metaphor. We can examine every item in an excerpt built on an extended metaphor to see what concept of knowledge it will trigger. The following metaphor is taken from V5:

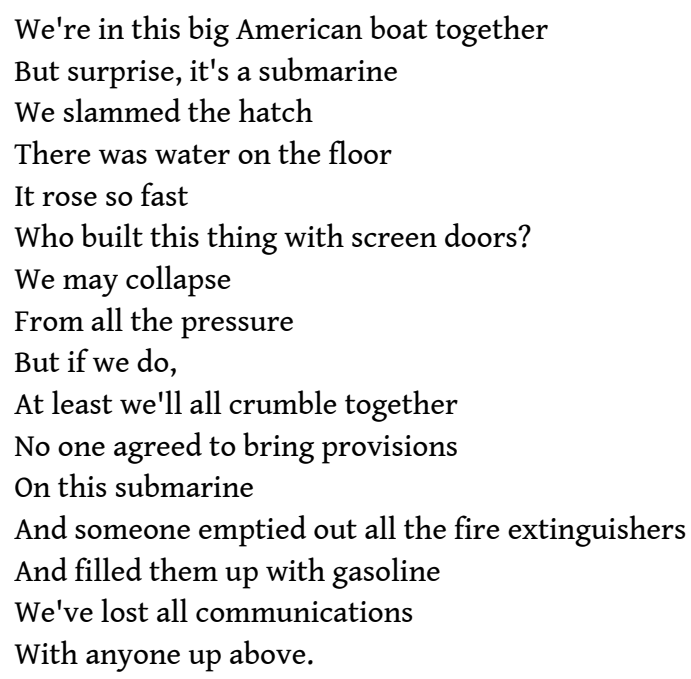

Each element in this metaphorical sequence relies on a stronger meaning. Two years worth of news is packed here. The sentence "We're in this big American boat together" - an echo of the idiom "to be on the same boat" - is used here to introduce the metaphor "The US is a submarine". The idea of a submarine - as opposed to a ship suggests an enclosed space, inescapable. A boat can also be a cruise ship, a transport ship, a ferry, but a submarine is most of the time a scientific tool or a powerful tool of warfare. The idea here seems to be that the country is at war against the rest of the world. "We slammed the hatch" refers to the isolationist politics promoted by Donald Trump and his people. From the start, during the campaign, the main political line was to put America first. Trump made it clear that international cooperation was not one of his interests. During the first two years of his presidency, he withdrew from the Paris Climate Agreement, triggered political conflicts with democratically elected world leaders - French President Emmanuel Macron, Canadian Prime Minister Justin Trudeau, German Chancellor Angela Merkel and most famously, only a few days after being sworn in, Australia's Prime Minister Malcolm Turnbull over immigration. "There was water on the floor" suggests that the submarine is already sinking. The "water" can refer to the many issues the country was facing at that time. Those issues were made worse by a schism between the two major ideologies. The schism was obvious during the debate over The Patient Protection and Affordable Act (or Obamacare for the 
opposition to the project). The rise of right-wing populism across the Western world, the massive immigration of people coming from countries at war, fleeing famine or natural catastrophes, the terrorists attacks, the remains of the 2008 financial crisis, tension over race, school shootings, police shootings, gun control, etc. The political tensions in the country increased in the wake of the presidential election and the close result. The 2016 election was, for most people, a last hope to fix what was perceived as a broken country. "It rose so fast" refers to the situation getting worse after the election. The solutions suggested, such as building a wall to stop immigration, caging up children, banning Muslims from entering the country, threatening war with Canada and others, were considered as immoral by most people. This phrase and the one before may be a reference to a common idiom in the US, "be in deep waters", which relates to an overwhelming situation. The next element that deserves attention is the use of "screen doors", which suggests the existence of a weak protection against outside attacks, and trouble coming from every side, as seen in the video. Screen doors are supposed to protect only against mosquitoes or other inconveniences, not against big issues. "We may collapse from all the pressure" reinforces the metaphor of a submarine while drawing a parallel with a plane and the depressurisation of a cabin, a device enhanced by the illustrations. The idea put forward here is that of an imploding country. Togetherness is important in this musical number, as suggested by the phrase "At least we'll all crumble together" which hints at imminent danger of collapse. However, knowing that they're "stuck here together", they might as well go down as a block rather than divided. The use of "provisions" might highlight the American way of financing the government that relies on a budget voted regularly. If the budget is not voted, then part of the Government is shut down. Under the Trump era (up until the song was made), the Government went through two shutdowns. The first one occurred on January 20, 2018, and lasted a little less than four days during which 600,000 employees lost their pay. The second one occurred three weeks later, for an agreement had not been found, but it lasted only a few hours, not long enough for federal employees to be furloughed. The image of "fire extinguishers" being filled up with "gasoline" might be a reference to diplomatic attempts made to avoid protests, stop investigations and keep international communications open and constantly undermined by the president or a member of his senior staff. Each crisis (a fire in this analogy) is exacerbated (by adding fuel to the fire): Kim Jung Hun criticises the government, Trump insults him via Twitter; more and more immigrants enter the US through the Southern border, Trump and his administration have the parents incarcerated and their children put in cages; arming teachers is considered as a means to avoid school shootings, etc. The last element of the metaphor, "We've lost all communications/ with anyone up above," relates to what has been said before about cutting communications with other democratically elected leaders. It can also be related to the idea that the American people is the chosen one and that they lost touch with the "bigman upstairs". In the metaphor, the United States is a submarine, while the other countries, especially allies, are boats hovering on the surface. The relationship between Donald Trump and America's allies has been endangered by the withdrawal of the Paris Climate Agreement, the tariffs placed on Canadian and European goods, the threats against Canada and Australia, the insults made to Germany and the German chancellor, etc.

19 Satire is therefore a potent combination of information and humour. It aims at rendering a message more understandable. It uses humour to do so, more specifically 
verbal humour. The Semantic Script Theory of Humour (or SSTH) plays on this distinction. In the branch of SSTH that concerns verbal humour - the General Theory of Verbal Humour (or GTVH) -, the forced passage from one base to the other creates humour. It does not always involve only one word but can be an association of several profiles belonging to the same base, the base being then switched more or less abruptly. A joke is always composed of three elements: a set-up, an incongruity and a punchline. The most common jokes, two-part jokes, consist of a set-up and a punchline, the incongruity occurring in either part. In the case of a three-part joke, the incongruity is then expressed on its own in the middle section and semantically separates, therefore, the set-up from the punchline.

In his book Speech Play and Verbal Art, Joel Sherzer defines a joke as follows:

"The term joke [...] refers to a discourse unit consisting of two parts: the set-up and the punchline. The punchline contains an element of surprise vis-à-vis the set-up; it is this surprising relationship between the set-up and the punchline that is the source of humour."

21 Jokes as a whole are defined by four aspects: the encyclopedic nature of their meaning, salience, the inclusion of discourse, prototypicality. Cognitive linguistics, as science, could provide answers to the question of how a joke is understood and identified as such. By confronting cognitive linguistics and humour, experts are acknowledging that the mechanisms are the same: conceptualisation, frame, space, structuring model, presupposition and usage-based language. Humour can be perceived as a marked, though not irregular, kind of language use.

Let us now consider the following three-part joke:

This time of year, I get thankful babe, thankful for you

But now you're gone and I don't know what to do

You were so intelligent, you were so strong

Waited my whole life for you so damn long.

And now I'm seeing you moving on

And I'm begging you to come back home.

Every night I turn the TV on and cry

I'll say why

I feel like we are all going to die

So come back Barack.

Here the set-up, the first part that ends with the phrase "come back home", is - as every set-up - a short text that explains the initial situation and expounds the first script (or base). The script is that of a romantic break-up and the departure of the singer's lover. The second part ending with "we are all going to die" is the incongruity. It is the pivotal part, for it lays bare the discrepancies between the two scripts present in the joke and denies, in a way, the meaning of the first script. The incongruity is gradual: the first section could still be related to the first script (a show that they may have watched together) but the second part ("I'll say why / I feel like we are all going to die") is out of place. It leads one to wonder why a break-up would affect "all" and why it would cause death. The third part of the joke, the punchline "So come back Barack" is where the first script is denied and the second comes into play. This explicit reference to Barack Obama and to the presence of his photograph in the music video creates humour because it solves the incongruity. This type of joke, where the difference between one script and the other is so obvious, is known as a garden-path joke. 
parisons and zeugma help a speaker relay information. Music and staging make it easier to remember. Puns and jokes make it fun. The combination of these three functions is what makes a satirical song a useful tool in spreading a message and, above all, what enables the message to leave an impact on its audience. Five videos do not, of course, provide enough data to eventually formulate a general theory on the constitution of parody songs, and their role in political satire. A larger corpus would be required to create a reliable model of analysis that could then be applied to other humorous and political songs, not only in the US but across the world.

\section{BIBLIOGRAPHY}

Basu, Laura. "News Satire: Giving the News a Memory.” TripleC: Communication, Capitalism \& Critique. Open Access Journal for a Global Sustainable Information Society, vol. 16, no. 1, 2018, pp. 241255., doi:10.31269/vol16iss1pp241-255.

Brône, Geert, Kurt Feyaerts, and Tony Veale. "Introduction: Cognitive Linguistic Approaches to Humor." International Journal of Humor Research 19.3 (2006): n. pag.

Croft, William, and D. A. Cruse. "Frames, Domains, Spaces: The Organization of Conceptual Structure"." Cognitive Linguistics. Cambridge: Cambridge UP, 2004. 7-39.

Raskin, Victor. "A Primer for the Linguistics of Humor." The Primer of Humor Research. Berlin: Mouton De Gruyter, 2008. 101-56.

Ritchie, Graeme. The Linguistic Analysis of Jokes. London: Routledge, 2014.

Sherzer, Joel. Speech Play and Verbal Art. Austin: U of Texas, 2002. Print.

"Satire." Oxford Encyclopedia of British Literature - Oxford Reference, Oxford University Press, 1 Dec. 2016, www.oxfordreference.com/view/10.1093/acref/9780195169218.001.0001/acref-9780195169218

"La Satire." EspaceFrancais.com, www.espacefrancais.com/.

Videos

ERB. "Donald Trump vs Hillary Clinton. Epic Rap Battles of History." YouTube. YouTube, 26 Oct. 2016. Web. 15 Feb. 2019. https://www.youtube.com/watch?

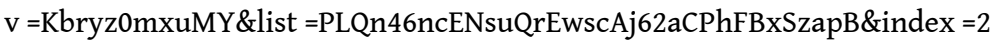

Live, Saturday Night. "Come Back, Barack - SNL." YouTube. YouTube, 18 Nov. 2017. Web. 15 Feb. 2019. https://www.youtube.com/watch?

$\mathrm{v}=$ ZkPSbp3zTfo\&list =PLQn46ncENsuQrEwscAj62aCPhFBxSzapB\&index =3

MoveOn. "LTH Crowd Favorite - Make America Great Again." YouTube. YouTube, 29 Sept. 2016. Web. 15 Feb. 2019. https://www.youtube.com/watch?

$\mathrm{v}=\mathrm{vf9K5KEs4rE \& list}=\mathrm{PLQn} 46 \mathrm{ncENsuQrEwscAj62aCPhFBxSzapB \& index}=1$

The Late Late Show with James Corden. "Trump to Robert Mueller: 'It Wasn't Me' (w/ Shaggy)." YouTube. YouTube, 14 Mar. 2018. Web. 15 Feb. 2019.https://www.youtube.com/ watchv $=$ qzt7JvsYIuI\&list $=$ PLQn46ncENsuQrEwscAj62aCPhFBxSzapB\&index $=4$ 
The Late Show with Stephen Colbert. "Stephen Sings 'We're Stuck In This Together'." YouTube. YouTube, 06 Nov. 2018. Web. 15 Feb. 2019. https://www.youtube.com/watch?

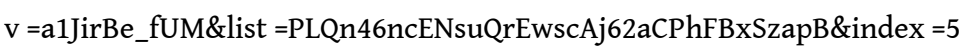

INDEX

Subjects: Music

Mots-clés: chansons parodiques, Donald Trump, satire politique, humour verbal, sémantique des cadres

Keywords: parody songs, Donald Trump, political satire, verbal humour, frame semantics

\section{AUTHORS}

\section{AURÉLIE DENAT}

Étudiante en Master 2 d'études anglophones Université Toulouse Jean Jaurès aurelie.pro.denat@gmail.com 